\title{
Estrutura da vegetação em florestas de mangue do estuário do rio Paraíba do Sul, Estado do Rio de Janeiro, Brasil ${ }^{1}$
}

\author{
Elaine Bernini² e Carlos Eduardo Rezende ${ }^{2}$
}

Recebido em 05/06/2003. Aceito em 17/12/2003

\begin{abstract}
RESUMO - (Estrutura da vegetação em florestas de mangue do estuário do rio Paraíba do Sul, Estado do Rio de Janeiro, Brasil). A estrutura da vegetação do manguezal do estuário do rio Paraíba do Sul foi analisada pelo método de parcelas, que foram distribuídas na franja e no interior da floresta em dois sítios de estudo. No geral, considerando-se os indivíduos $\geq 1 \mathrm{~m}$ alt., a altura média variou de 6,3 a 9,9m, o DAP médio de 7,44 a 13,4cm, a área basal média de 14,5 a 35,3 $\mathrm{m}^{2} . \mathrm{ha}^{-1}$ e a densidade média de 1.920 a 3.400 troncos.ha ${ }^{-1}$. Estes parâmetros estruturais não diferiram, significativamente, entre a franja e o interior da floresta, mas a contribuição de cada espécie variou entre as distintas zonas. Avicennia germinans (L.) Stearn. foi a espécie dominante em área basal de indivíduos vivos (60\%), seguida de Rhizophora mangle L. (25\%) e de Laguncularia racemosa (L.) Gaertn. (15\%). Os resultados obtidos demonstraram que a área de manguezal analisada apresenta melhor desenvolvimento estrutural quando comparada a outros manguezais do litoral fluminense, tais como os encontrados nas Baías de Guanabara e Sepetiba.
\end{abstract}

Palavras-chave: estrutura da vegetação, estuário do rio Paraíba do Sul, manguezal

\begin{abstract}
Vegetation structure of the mangrove forest at the estuary Paraíba do Sul river, Rio de Janeiro, Brazil). A structural analysis of the mangrove forest at the Paraíba do Sul river estuary was performed using the stand method. The stands were demarcated in two points both at the forest edge and interior. The results indicate that average height varied from 6.3 to $9.9 \mathrm{~m}$; $\mathrm{DBH}$ varied from 7.44 to $13.4 \mathrm{~cm}$; average basal area varied from 14.5 to $35.3 \mathrm{~m}^{2}$.ha ${ }^{-1}$, and average density varied from 1,920 to 3,400 trunks.ha-1 (trees $\geq 1 \mathrm{~m}$ height). These structural parameters did not differ between the edge and the interior, but the contribution of each species varied between the zones. Avicennia germinans (L.) Stearn. was the dominant species (60\%), followed by Rhizophora mangle L. (25\%), and Laguncularia racemosa (L.) Gaertn. (15\%). These results demonstrate that the mangroves forest at the Paraíba do Sul estuary has a better structural development than other mangrove sites found in the Rio de Janeiro State (e.g., those mangrove forests located at the Sepetiba and Guanabara bays).
\end{abstract}

Key words: vegetation structure, Paraíba do Sul River Estuary, mangrove

\section{Introdução}

O manguezal é um ecossistema de elevada importância ecológica, social e econômica, e também considerado dominante na fisiografia do litoral do Brasil, distribuindo-se ao longo dos $6.800 \mathrm{~km}$ da linha costeira, sendo a estimativa mais recente, para a área de cobertura calculada em 1,38 milhão de hectares (Kjerfve \& Lacerda 1993).

Do ponto de vista ecológico, o manguezal tem sido estudado sob os aspectos estrutural e funcional. O estudo da estrutura inclui informações sobre diversidade, altura, diâmetro, área basal, densidade, distribuição por classe etária e padrões de distribuição espacial das espécies componentes da floresta; na óptica funcional, estuda-se a ciclagem de nutrientes e fluxos de energia no ecossistema (Lugo \& Snedaker 1974; Smith 1992).

O estudo da estrutura da vegetação fornece idéia do grau de desenvolvimento da floresta de mangue, possibilitando a identificação e a delimitação de florestas com características semelhantes, o que permite realizar comparações entre áreas diferentes (Schaeffer-Novelli \& Cintrón 1986). No manguezal, vários tipos de estresse aumentam com a distância da linha d'água, e os efeitos relacionados à inundação pelas marés (acúmulo de sais, granulometria, intensidade das ondas) resultam em condições que podem prejudicar o desenvolvimento das plantas (Fry et al. 2000). A caracterização estrutural dos manguezais constitui valiosa ferramenta no que concerne à resposta desse ecossistema às condições ambientais existentes, bem

\footnotetext{
1 Parte da Dissertação de Mestrado da primeira Autora; Universidade Estadual do Norte Fluminense (UENF); Centro de Biociências e Biotecnologia; Laboratório de Ciências Ambientais - LCA/CBB/UENF, Av. Alberto Lamego, 2000, Horto, CEP 28013-602, Campos dos Goytacazes, RJ, Brasil

2 Autor para correspondência: bernini@uenf.br
} 
como aos processos de alteração do meio ambiente, auxiliando, assim, nos estudos e ações que objetivam a conservação do ecossistema (Soares 1999).

Ao longo da costa brasileira, os manguezais apresentam-se com características estruturais bastante distintas. Para auxiliar a interpretação das florestas de mangue brasileiras, Schaeffer-Novelli et al. (1990) dividiram o litoral do país em oito unidades fisiográficas, levando-se em consideração a cobertura vegetal e as características ambientais. De acordo com essa divisão, cada unidade apresentaria um desenvolvimento estrutural similar, por estar submetida às mesmas condições ambientais regionais.

No Estado do Rio de Janeiro, as áreas mais extensas de manguezal são a foz do rio Paraíba do Sul e as baías de Guanabara, Sepetiba e Angra dos Reis (FEEMA 1980; Menezes et al. 2000). No Estado, onde o manguezal ocupa área de aproximadamente $16.000 \mathrm{~km}^{2}$ (Kjerfve \& Lacerda 1993), ocorrem as espécies típicas Avicennia germinans (L.) Stearn., Avicennia schaueriana Stapft \& Leechm., Laguncularia racemosa (L.) Gaertn. e Rhizophora mangle L. Segundo a classificação de SchaefferNovelli et al. (1990), os manguezais do Norte Fluminense estão incluídos na Unidade VI, que vai do

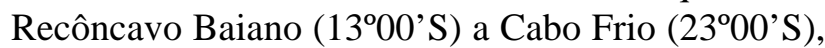
sendo que os maiores são encontrados na foz dos três principais rios do litoral norte: Itabapoana, Paraíba do Sul e Macaé.

Existem poucas informações sobre estudos dos atributos estruturais, funcionais e da dinâmica dos manguezais do Estado do Rio de Janeiro, tornando difícil a determinação de um padrão estrutural para o ecossistema neste Estado (Soares 1999). Entretanto, devem ser destacados os trabalhos desenvolvidos em manguezais da Baía de Guanabara (Araújo \& Maciel 1979), Baía de Sepetiba (Silva et al. 1991; Pellegrini et al. 2000; Oliveira et al. 2000) e Lagoa da Tijuca (Soares 1999). Dentro deste contexto, os objetivos do presente estudo foram conhecer e caracterizar a estrutura da vegetação de duas florestas de mangue do estuário do rio Paraíba do Sul, Estado do Rio de Janeiro e verificar o potencial efeito da variação espacial (franja e interior da floresta) nos parâmetros estruturais analisados.

\section{Material e métodos}

Área de estudo - O estuário do rio Paraíba do Sul, situado ao norte da costa do Estado do Rio de Janeiro, é classificado como um delta em forma de cúspide, caracterizado pelo desenvolvimento de cristas de praia nos lados do canal. Possui uma saída denominada Estuário Principal, na região de Atafona (Município de São João da Barra), e outra saída, o Estuário Secundário, ao norte da desembocadura, nas proximidades de Gargaú (Município de São Francisco do Itabapoana) (Fig. 1). Este estuário apresenta uma planície formada por sucessão de faixas arenosas alongadas que apresentam limites, largura e extensões variáveis, intercaladas por terrenos superficialmente argilosos, onde se desenvolvem áreas de manguezais.

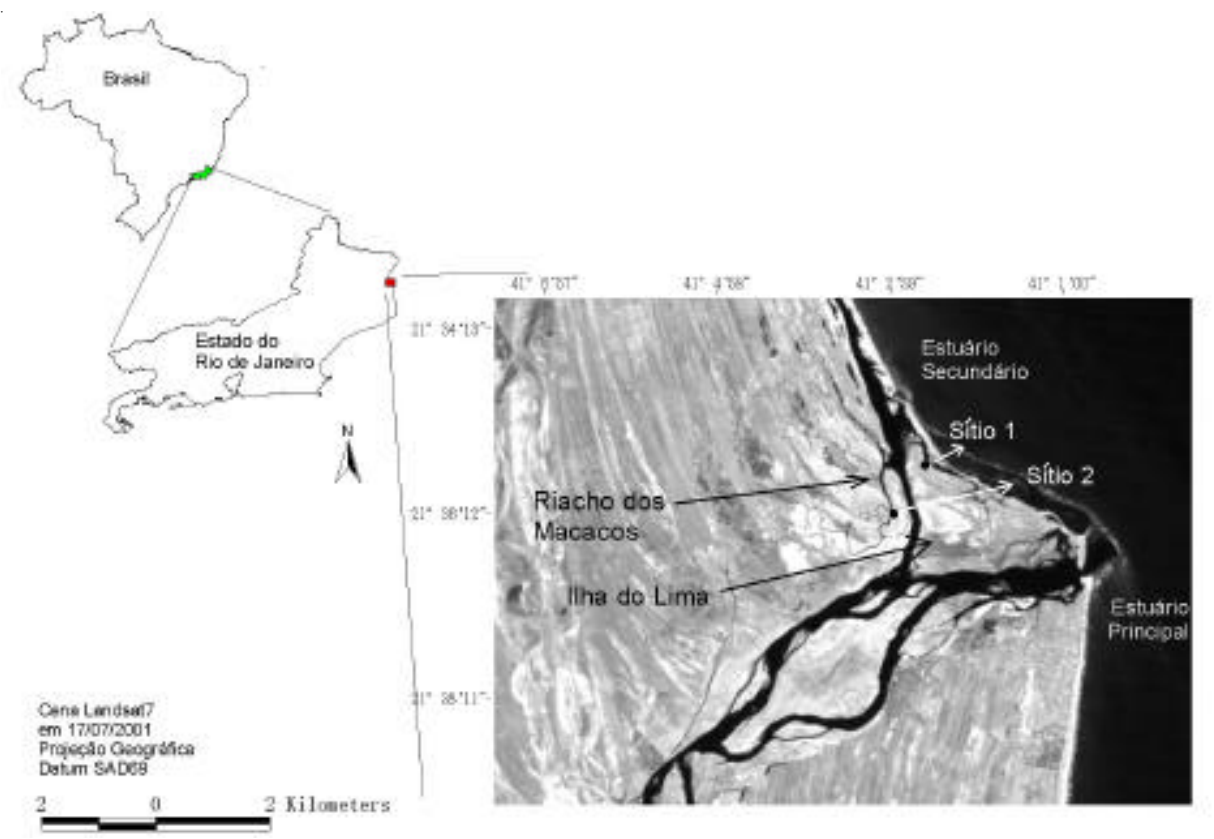

Figura 1. Localização dos sítios de estudo analisados no manguezal do estuário do rio Paraíba do Sul, Estado do Rio de Janeiro, Brasil. 
O manguezal do estuário do rio Paraíba do Sul é o maior da região Norte Fluminense, com aproximadamente 800 ha, cuja floresta é constituída por A. germinans, L. racemosa e $R$. mangle. Este manguezal tem sido alvo de freqüentes ações de degradação, como atividade extrativista de árvores, invasão da pecuária, urbanização, obras de dragagem efetuada no canal principal e abertura de novos canais. Há ainda a captura predatória do caranguejo Ucides cordatus mediante a colocação de pequenas redes nas bocas das galerias, prática que não distingue macho de fêmea, ou mesmo o adulto do jovem, o que desequilibra as populações da espécie.

O presente estudo foi conduzido no manguezal de Gargaú, situado no Estuário Secundário do rio, no município de São Francisco do Itabapoana (2136'00”S e $\left.41^{\circ} 03^{\prime} 00^{\prime \prime} \mathrm{W}\right)$. Dois sítios foram selecionados em locais com pouca interferência antrópica, ou seja, com ausência de lixo, lançamento de efluentes orgânicos e inorgânicos e aterro. Em campo foram observadas apenas algumas árvores cortadas. O Sítio 1 foi estabelecido na Ilha do Lima e o Sítio 2, no local conhecido como riacho dos Macacos (Fig. 1). Afloresta de mangue encontrada às margens deste riacho é considerada a mais preservada do estuário do rio Paraíba do Sul. Segundo a classificação de Lugo \& Snedaker (1974) e Cintrón et al. (1980), as florestas de mangue estudadas são do tipo fisiográfico ribeirinho, o qual margeia rios e canais de maré e exibe melhor desenvolvimento estrutural quando comparado aos outros tipos fisiográficos (franja e bacia).

O clima predominante é o do tipo Aw (quente e úmido com chuvas de verão), com temperatura média mínima de $18^{\circ} \mathrm{C}$ e média máxima de $24^{\circ} \mathrm{C}$. A precipitação média anual encontra-se entre $1.000 \mathrm{e}$ $1.250 \mathrm{~mm}$ (DNAEE 1993). Baseado em dados do Terminal da Ponta do Ubu, Estado do Espírito Santo ( $20^{\circ} 44^{\prime}$ S; $40^{\circ} 32^{\prime} \mathrm{W}$ ), no período entre 2001 e 2002, a média das marés foi de $0,8 \mathrm{~m}$, com o intervalo médio de 0,2 e 1,3m (DHN 2001).

\section{Material e métodos}

O estudo foi realizado no período de agosto/2001 a julho/2002. Durante a baixa-mar, foram coletadas três amostras aleatórias de sedimento superficial $(0-15 \mathrm{~cm})$ em cada parcela delimitada para o estudo da estrutura da vegetação. As amostras foram colocadas em sacos plásticos e transportadas, sob refrigeração, para o Laboratório de Ciências Ambientais (LCA), da Universidade Estadual do Norte
Fluminense (UENF), onde foram congeladas para análises posteriores. Após este procedimento, o sedimento foi liofilizado e fez-se a remoção de fragmentos grosseiros e pedaços de raízes em peneira de aço inox de 2,0 $\mathrm{mm}$. Posteriormente, o material foi armazenado em caixas de acrílico.

Amostras de $20 \mathrm{~g}$ de sedimento passaram por peneiramento em agitador mecânico durante um período de 30 minutos para análise granulométrica, tendo sido separadas as frações silte/argila

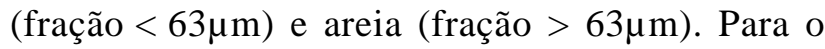
cálculo do percentual de recuperação durante o processo de determinação das frações silte/argila e areia, foi utilizado a soma da massa destas frações após peneiração, dividida pela massa inicial $(20 \mathrm{~g})$. A média final de recuperação foi de $97 \%$. Sub-amostras de sedimento $(2 \mathrm{~g})$ foram incineradas em forno mufla $\left(450^{\circ} \mathrm{C} / 24 \mathrm{~h}\right)$ para posterior cálculo do percentual de matéria orgânica. Para análise de $\mathrm{pH}$, foram adicionados $25 \mathrm{~mL}$ de água em $10 \mathrm{~g}$ de sedimento. As amostras foram agitadas com bastão de vidro e mantidas em repouso durante uma hora (EMBRAPA 1997). Posteriormente, procedeu-se à leitura em potenciômetro DMPH-3 Digimed (previamente aferido com padrões de pH 4,0 e 7,0). Após três horas, determinou-se a condutividade elétrica (Microprocessor Condutivity Meter), na mesma suspensão homogeneizada.

A estrutura da vegetação foi analisada de acordo com a metodologia descrita em Schaeffer-Novelli \& Cintrón (1986), que consiste no emprego do método de parcelas múltiplas. Em cada sítio de estudo (Fig. 1), foram demarcados dois grupos de três parcelas, distanciadas em $30 \mathrm{~m}$ e paralelas à margem do rio, ficando o primeiro grupo a $10 \mathrm{~m}$ (franja) e o segundo, a $70 \mathrm{~m}$ da margem do canal (interior). No Sítio 1 , as parcelas 1, 2 e 3 foram alocadas na franja e as parcelas 4,5 e 6 , no interior da floresta. No Sítio 2 , as parcelas 7,8 e 9 situaram-se na franja e as de número $10,11 \mathrm{e}$ 12 , no interior da floresta. A área das parcelas variou de 100 a $300 \mathrm{~m}^{2}$, totalizando 0,26 ha. O tamanho das parcelas foi determinado em função da densidade da vegetação e da uniformidade da floresta, sendo que dentro de cada parcela foram incluídos, no mínimo, de 20 a 30 árvores (Schaeffer-Novelli \& Cintrón 1986).

Em cada parcela, as plantas foram identificadas quanto à espécie e o material botânico foi coletado. Foram anotadas a altura (estimada com auxílio de vara telescópica) e a circunferência (com o auxílio de fita métrica e correspondente ao DAP, diâmetro a 1,30m de altura do solo) dos troncos de todos os indivíduos acima de $1 \mathrm{~m}$ alt. e com a base do caule no interior da 
parcela. No caso dos indivíduos menores que $1,30 \mathrm{~m}$ de altura, o DAP foi substituído pelo diâmetro do tronco abaixo da primeira ramificação (Soares 1999). Para a espécie $R$. mangle, a medida da circunferência foi efetuada acima do último rizóforo, quando necessário.

Posteriormente, os dados de circunferência dos troncos vivos e mortos foram transformados em diâmetro à altura do peito $(\mathrm{DAP}=\mathrm{CAP} / \pi)$ e foram calculados, para cada parcela, a altura média, o DAP médio, a área basal de indivíduos vivos e mortos por espécie e classe diamétrica, a densidade de troncos vivos e mortos, a dominância em área basal e a densidade relativa de troncos (Schaeffer-Novelli \& Cintrón 1986).

Quanto à análise estatística, primeiramente, foi feita análise descritiva (média e desvio padrão) dos dados referentes aos parâmetros analisados no sedimento e à estrutura da vegetação. Posteriormente, as variáveis foram submetidas à ANOVA two-way para detectar diferenças entre zonas (franja e interior) e sítios de estudo. Foi calculado o coeficiente de correlação de Pearson para as variáveis matéria orgânica $\times$ silte/argila. Os valores críticos foram considerados significativos para $\mathrm{p} \leq 0,05$.

\section{Resultados}

Sedimento - Na Tabela 1 são apresentados os valores médios das variáveis ambientais determinadas no sedimento, e na Tabela 2, os resultados da ANOVA two-way realizada para os dados. Os parâmetros analisados no sedimento não diferiram, significativamente, entre a franja e o interior da floresta. Dentre as variáveis, apenas o percentual de matéria orgânica apresentou diferença significativa entre os sítios de estudo, sendo mais elevado no Sítio 2. Os valores de condutividade elétrica foram baixos e exibiram grande variação entre as parcelas. No Sítio 1, os valores das parcelas oscilaram entre 380 e $897 \mu{\mathrm{S} . \mathrm{cm}^{-1}}^{\text {e no Sítio }}$ 2 , entre 378 e $1.149 \mu{\mathrm{S} . \mathrm{cm}^{-1}}^{-}$A fração areia foi predominante em ambos os sítios. O percentual de matéria orgânica foi considerado alto, apesar do sedimento ser arenoso; entretanto, o conteúdo de matéria orgânica não apresentou correlação significativa com a fração silte/argila. $\mathrm{O}$ pH foi levemente ácido e com pouca variação entre as zonas e os sítios de estudo, com o menor valor sendo registrado na parcela P9 do Sítio $2(4,95)$ e o maior, na parcela P4 do Sítio $1(5,98)$.

Estrutura da vegetação - Nos dois sítios de estudo foram registradas três espécies de árvore: Avicennia germinans (L.) Stearn. (Avicenniaceae), Laguncularia racemosa (L.) Gaertn. (Combretaceae) e Rhizophora mangle L. (Rhizophoraceae). Além disso, também foram registradas as espécies associadas Acrostichum aureum L. (Pteridaceae) e Hibiscus pernambucensis Arruda (Malvaceae).

Considerando-se os dois sítios, a altura variou de 1,10 a $19,5 \mathrm{~m}$, com média de $8,1 \pm 3,9 \mathrm{~m}$. A altura média foi significativamente mais elevada no Sítio 2 , sem diferença significativa entre a franja e o interior da floresta (Tab. 3 e 4). A maior altura foi estimada em A. germinans $(19,5 \mathrm{~m})$, enquanto que os indivíduos mais altos de $L$. racemosa e $R$. mangle atingiram 12,3 e $14,5 \mathrm{~m}$, respectivamente. A distribuição dos indivíduos em classes de altura indicou diferença na altura do dossel entre os sítios (Fig. 2). No Sítio 1, não se registrou indivíduos acima de $18 \mathrm{~m}$, estando a maior parte dos indivíduos representada na classe entre 6,1 e $8,0 \mathrm{~m}$, enquanto que no Sítio 2 , as árvores

Tabela 1. Variáveis ambientais determinadas no sedimento das parcelas na franja e no interior da floresta nos dois sítios de estudo analisados no manguezal do estuário do rio Paraíba do Sul, Rio de Janeiro, Brasil (média \pm desvio padrão).

\begin{tabular}{|c|c|c|c|c|c|}
\hline Sítio/zona & $\begin{array}{l}\text { Condutividade } \\
\left(\mu \mathrm{S} . \mathrm{cm}^{-1}\right)\end{array}$ & $\begin{array}{c}\text { Silte/Argila } \\
(\%)\end{array}$ & $\begin{array}{l}\text { Areia } \\
(\%)\end{array}$ & $\begin{array}{l}\text { Matéria orgânica } \\
(\%)\end{array}$ & $\mathrm{pH}$ \\
\hline \multicolumn{6}{|l|}{ Sítio 1} \\
\hline Franja $(n=3)$ & $667 \pm 199$ & $37,6 \pm 9,92$ & $62,4 \pm 9,92$ & $13,6 \pm 0,95$ & $5,37 \pm 0,16$ \\
\hline Interior $(n=3)$ & $531 \pm 176$ & $34,0 \pm 8,07$ & $66,0 \pm 8,07$ & $14,5 \pm 5,32$ & $5,82 \pm 0,25$ \\
\hline Geral $(n=6)$ & $631 \pm 184$ & $37,2 \pm 8,33$ & $62,8 \pm 8,33$ & $15,1 \pm 3,46$ & $5,69 \pm 0,31$ \\
\hline \multicolumn{6}{|l|}{ Sítio 2} \\
\hline Franja $(n=3)$ & $674 \pm 416$ & $32,8 \pm 5,04$ & $67,2 \pm 5,04$ & $16,0 \pm 1,25$ & $5,33 \pm 0,34$ \\
\hline Interior $(n=3)$ & $712 \pm 92$ & $25,7 \pm 9,71$ & $74,3 \pm 9,71$ & $16,6 \pm 6,79$ & $5,33 \pm 0,17$ \\
\hline Geral $(n=6)$ & $724 \pm 270$ & $27,7 \pm 7,94$ & $72,3 \pm 7,94$ & $16,3 \pm 4,38$ & $5,38 \pm 0,24$ \\
\hline
\end{tabular}


Tabela 2. Resultados da análise estatística (ANOVA two-way) mostrando diferenças significativas $(* p \leq 0,05)$ nas zonas (franja $\times$ interior) e sítios $(1 \times 2)$ nos valores das variáveis ambientais determinadas no sedimento das parcelas analisadas no manguezal do estuário do rio Paraíba do Sul, Rio de Janeiro, Brasil.

\begin{tabular}{|c|c|c|c|c|c|}
\hline Efeito & Condutividade & Silte/argila & Areia & $\begin{array}{l}\text { Matéria } \\
\text { organica }\end{array}$ & $\mathrm{pH}$ \\
\hline Zona $(Z ; n=3)$ & 0,71 & 1,00 & 1,00 & 0,09 & 0,38 \\
\hline Sítio $(S ; n=6)$ & 0,76 & 0,84 & 0,84 & $\mathbf{0 , 0 3} *$ & 0,14 \\
\hline $\mathrm{Z} \times \mathrm{S}$ & 0,78 & 0,54 & 0,54 & 0,15 & 0,19 \\
\hline
\end{tabular}

apresentaram porte mais elevado, estando a maioria representada na classe entre 8,1 e $10,0 \mathrm{~m}$.

O DAP médio geral foi de $10,3 \mathrm{~cm}$, sendo mais elevado para o Sítio 2 (Tab. 3 e 4). Os valores não diferiram, significativamente, entre a franja e o interior da floresta. O menor DAP médio foi registrado na parcela P1 do Sítio $1(6,29 \mathrm{~cm})$ e o maior, na P11 do Sítio $2(16,7 \mathrm{~cm})$.

Em relação à área basal dos indivíduos vivos, verificou-se menor amplitude e valores mais baixos no Sítio 1, em relação ao Sítio 2 (Tab. 3). Este parâmetro não apresentou diferença significativa entre a franja e o interior da floresta (Tab. 4). Considerando-se a área basal total de indivíduos vivos, A. germinans foi a espécie dominante $(60 \%)$, seguida de $R$. mangle (25\%) e de L. racemosa (15\%). Entretanto, a contribuição de cada espécie diferiu entre as zonas e entre os sítios. No Sítio 1 houve co-dominância de A. germinans (42\%) com L. racemosa (41\%). Neste sítio, L. racemosa foi dominante na franja e A. germinans, no interior da floresta (Tab. 5). No Sítio 2 , a contribuição de A. germinans foi de $70 \%$, seguida de $R$. mangle, com $29 \%$ e de L. racemosa, com apenas $1 \%$, sendo que A. germinans foi dominante na franja e $R$. mangle no interior da floresta (Tab. 5). A contribuição em área basal de troncos vivos variou entre a franja e o interior da floresta nas diversas classes diamétricas (Tab. 6). A contribuição dos troncos com diâmetro $\geq 10,0 \mathrm{~cm}$ foi alta, atingindo os maiores valores no Sítio 2. No Sítio 1, A. germinans e L. racemosa mostraram maior contribuição na classe diamétrica $\geq 10,0 \mathrm{~cm}$ e $R$. mangle, na classe intermediária. No Sítio 2, as três espécies exibiram maior contribuição na classe superior (Tab. 7).

Quanto à área basal dos indivíduos mortos, os valores foram mais altos no Sítio 1 (Tab. 3), sem

Tabela 3. Parâmetros estruturais analisados na franja e no interior da floresta nos dois sítios de estudo analisados no manguezal do estuário do rio Paraíba do Sul, Rio de Janeiro, Brasil (média đdesvio padrão).

\begin{tabular}{|c|c|c|c|c|c|c|}
\hline Sítio/zona & Altura $^{1}$ & DAP médio ${ }^{2}$ & $\begin{array}{c}\text { Área basal } \\
\text { indivíduos vivos }^{3}\end{array}$ & $\begin{array}{c}\text { Área basal } \\
\text { indivíduos mortos }\end{array}$ & $\begin{array}{c}\text { Densidade } \\
\text { troncos vivos }\end{array}$ & $\begin{array}{c}\text { Densidade } \\
\text { troncos mortos }\end{array}$ \\
\hline \multicolumn{7}{|l|}{ Sítio 1} \\
\hline Franja $(n=3)$ & $6,3 \pm 0,5$ & $7,44 \pm 1,26$ & $14,5 \pm 2,50$ & $3,41 \pm 2,93$ & $3.40 \pm 546$ & $1.05 \pm 589$ \\
\hline Interior $(n=3)$ & $8,0 \pm 0,3$ & $9,99 \pm 0,88$ & $15,0 \pm 2,25$ & $6,19 \pm 0,41$ & $1.920 \pm 243$ & $1.115 \pm 269$ \\
\hline Geral $(n=6)$ & $7,1 \pm 1,0$ & $8,71 \pm 1,70$ & $14,7 \pm 2,14$ & $4,80 \pm 2,41$ & $2.660 \pm 895$ & $1.083 \pm 411$ \\
\hline \multicolumn{7}{|l|}{ Sítio 2} \\
\hline Franja $(n=3)$ & $9,9 \pm 0,2$ & $13,4 \pm 1,30$ & $35,3 \pm 14,9$ & $2,37 \pm 1,06$ & $2.600 \pm 1.600$ & $1.202 \pm 1.218$ \\
\hline Interior $(n=3)$ & $9,5 \pm 2,5$ & $11,7 \pm 4,33$ & $18,2 \pm 3,99$ & $1,38 \pm 1,21$ & $1.928 \pm 794$ & $255 \pm 214$ \\
\hline Geral $(n=6)$ & $9,7 \pm 1,6$ & $12,6 \pm 3,00$ & $26,7 \pm 13,5$ & $1,88 \pm 1,15$ & $2.294 \pm 1.199$ & $729 \pm 939$ \\
\hline
\end{tabular}

$1=\mathrm{m} ; 2$ = média do DAP médio, em $\mathrm{cm} ; 3=\mathrm{m}^{2} \cdot \mathrm{ha}^{-1} ; 4=$ troncos.ha $^{-1}$

Tabela 4. Resultados da análise estatística (ANOVA two-way) mostrando diferenças significativas (*p $\leq 0,05)$ entre zonas (franja $\times$ interior) e sítios $(1 \times 2)$ nos parâmetros estruturais analisados no manguezal do estuário do rio Paraíba do Sul, Rio de Janeiro, Brasil.

\begin{tabular}{lcccccc}
\hline Efeito & Altura & DAP médio & $\begin{array}{c}\text { Área basal } \\
\text { indivíduos vivos }\end{array}$ & $\begin{array}{c}\text { Área basal } \\
\text { indivíduos mortos }\end{array}$ & $\begin{array}{c}\text { Densidade } \\
\text { troncos vivos }\end{array}$ & $\begin{array}{c}\text { Densidade } \\
\text { troncos mortos }\end{array}$ \\
\hline Zona $(\mathrm{Z} ; \mathrm{n}=3)$ & 0,44 & 0,57 & 0,11 & 0,38 & 0,08 & 0,31 \\
Sítio $(\mathrm{S} ; \mathrm{n}=6)$ & $<\mathbf{0 , 0 1 *}$ & $\mathbf{0 , 0 2 *}$ & $\mathbf{0 , 0 3 *}$ & $<\mathbf{0 , 0 1 *}$ & 0,52 & 0,41 \\
$\mathrm{Z} \times \mathrm{S}$ & 0,18 & 0,43 & 0,09 & 0,09 & 0,51 & 0,24 \\
\hline
\end{tabular}




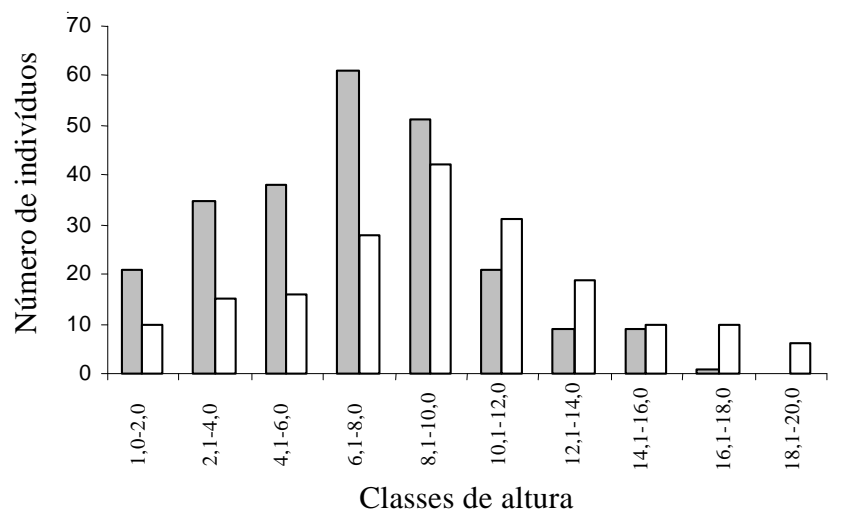

Figura 2. Distribuição dos indivíduos em classes de altura (m) nos dois sítios de estudo analisados no manguezal do estuário do rio Paraíba do Sul, Rio de Janeiro, Brasil (Sítio 1 n $=246$ e Sítio 2 $\mathrm{n}=187)$. $\square=$ Sítio $1 ; \square=$ Sítio 2 .

diferença entre a franja e o interior da floresta (Tab. 4). No Sítio 1, registrou-se grande contribuição em área basal de indivíduos mortos de L. racemosa, enquanto que no Sítio 2, a maior contribuição foi de A. germinans (Tab. 5). No Sítio 1, a maior contribuição em área basal de troncos mortos ocorreu nas classes intermediária e superior e no Sítio 2, na classe $\geq 10,0 \mathrm{~cm}$ (Tab. 6). Analisando-se separadamente as espécies, confirma-se para todas, a maior contribuição na classe intermediária no Sítio 1. Por outro lado, no Sítio 2, $R$. mangle exibiu maior contribuição na classe intermediária, e A. germinans e L. racemosa, na classe superior (Tab. 7).

A relação tronco/indivíduo foi semelhante entre zonas e sítios de estudo (Tab. 8). A densidade total de troncos vivos não diferiu entre os sítios, mas foi maior na franja da floresta, apesar de não ser estatisticamente significativa (Tab. 3 e 4). Quanto aos troncos mortos, a densidade foi mais elevada no Sítio 1, apesar da diferença não ser significativa (Tab. 3 e 4). No Sítio 1 , L. racemosa apresentou maior densidade tanto de troncos vivos quanto de troncos mortos, enquanto que

Tabela 5. Área basal $\left(\mathrm{m}^{2} \cdot \mathrm{ha}^{-1}\right)$ de indivíduos vivos e mortos, por espécie, na franja e no interior da floresta nos dois sítios de estudo

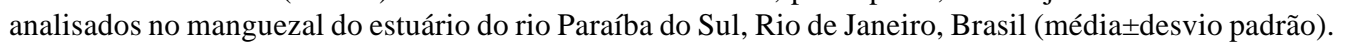

\begin{tabular}{|c|c|c|c|c|c|c|}
\hline \multirow[t]{2}{*}{ Sítio/zona } & \multicolumn{3}{|c|}{ Área basal de indivíduos vivos } & \multicolumn{3}{|c|}{ Área basal de indivíduos mortos } \\
\hline & $\mathrm{Ag}$ & $\operatorname{Lg}$ & $\mathrm{Rh}$ & $\mathrm{Ag}$ & $\mathrm{Lg}$ & $\mathrm{Rh}$ \\
\hline \multicolumn{7}{|l|}{ Sítio 1} \\
\hline Franja $(n=3)$ & $3,95 \pm 5,14$ & $6,67 \pm 1,44$ & $3,85 \pm 2,12$ & $0,07 \pm 0,00$ & $3,31 \pm 3,00$ & $0,22 \pm 0,00$ \\
\hline Interior $(n=3)$ & $8,39 \pm 1,76$ & $5,48 \pm 0,64$ & $1,09 \pm 0,26$ & $0,21 \pm 0,24$ & $5,98 \pm 0,25$ & - \\
\hline Geral $(n=6)$ & $6,17 \pm 4,21$ & $6,08 \pm 1,19$ & $2,47 \pm 2,03$ & $0,17 \pm 0,21$ & $4,65 \pm 2,40$ & $0,22 \pm 0,00$ \\
\hline \multicolumn{7}{|l|}{ Sítio 2} \\
\hline Franja $(n=3)$ & $31,6 \pm 18,2$ & $0,54 \pm 0,00$ & $5,30 \pm 0,65$ & $2,11 \pm 1,25$ & $0,19 \pm 0,00$ & $0,59 \pm 0,00$ \\
\hline Interior $(n=3)$ & $8,97 \pm 7,40$ & $0,59 \pm 0,02$ & $11,9 \pm 3,98$ & $1,36 \pm 1,73$ & $0,61 \pm 0,00$ & $0,42 \pm 0,29$ \\
\hline Geral (n=6) & $22,5 \pm 18,3$ & $0,57 \pm 0,03$ & $9,24 \pm 4,58$ & $1,81 \pm 1,31$ & $0,40 \pm 0,30$ & $0,47 \pm 0,23$ \\
\hline
\end{tabular}

$\mathrm{Ag}=$ Avicennia germinans $; \mathrm{Lg}=$ Laguncularia racemosa $; \mathrm{Rh}=$ Rhizophora mangle

Tabela 6. Área basal $\left(\mathrm{m}^{2} \cdot \mathrm{ha}^{-1}\right)$ de indivíduos vivos e mortos, por classe diamétrica $(\mathrm{cm})$, na franja e no interior da floresta nos dois sítios de estudo analisados no manguezal do estuário do rio Paraíba do Sul, Rio de Janeiro, Brasil (média desvio padrão).

\begin{tabular}{|c|c|c|c|c|c|c|}
\hline \multirow[t]{2}{*}{ Sítio/zona } & \multicolumn{3}{|c|}{ Área basal de indivíduos vivos } & \multicolumn{3}{|c|}{ Área basal de indivíduos mortos } \\
\hline & $<2,5 \mathrm{~cm}$ & $\geq 2,5 \mathrm{~cm}$ & $\geq 10,0 \mathrm{~cm}$ & $<2,5 \mathrm{~cm}$ & $\geq 2,5 \mathrm{~cm}$ & $\geq 10,0 \mathrm{~cm}$ \\
\hline \multicolumn{7}{|l|}{ Sítio 1} \\
\hline Franja $(n=3)$ & $0,27 \pm 0,11$ & $5,97 \pm 0,23$ & $8,24 \pm 2,47$ & $0,02 \pm 0,01$ & $2,40 \pm 1,77$ & $1,50 \pm 1,28$ \\
\hline Interior $(\mathrm{n}=3)$ & $0,11 \pm 0,06$ & $3,05 \pm 1,00$ & $11,9 \pm 2,66$ & - & $2,94 \pm 1,22$ & $3,25 \pm 1,01$ \\
\hline Geral $(n=6)$ & $0,19 \pm 0,12$ & $4,51 \pm 1,72$ & $10,0 \pm 3,02$ & $0,01 \pm 0,01$ & $2,67 \pm 1,39$ & $2,60 \pm 1,40$ \\
\hline \multicolumn{7}{|l|}{ Sítio 2} \\
\hline Franja $(n=3)$ & $0,09 \pm 0,02$ & $3,15 \pm 2,21$ & $32,1 \pm 12,9$ & $0,18 \pm 0,10$ & $1,11 \pm 0,50$ & $1,14 \pm 0,46$ \\
\hline Interior $(n=3)$ & $0,07 \pm 0,08$ & $3,28 \pm 1,52$ & $14,9 \pm 5,59$ & $0,08 \pm 0,00$ & $0,30 \pm 0,29$ & $1,60 \pm 1,39$ \\
\hline Geral $(n=6)$ & $0,08 \pm 0,04$ & $3,22 \pm 1,70$ & $23,5 \pm 12,9$ & $0,15 \pm 0,09$ & $0,70 \pm 0,57$ & $1,32 \pm 0,81$ \\
\hline
\end{tabular}


Tabela 7. Dominância em área basal (DoA) e densidade relativa (DR) de troncos vivos e mortos, por classe diamétrica ( $\mathrm{cm}$ ) e espécies nos dois sítios de estudo analisados no manguezal do estuário do rio Paraíba do Sul, Rio de Janeiro, Brasil.

\begin{tabular}{|c|c|c|c|c|c|c|c|c|c|c|c|c|c|c|c|c|c|c|}
\hline & \multicolumn{9}{|c|}{ Troncos vivos } & \multicolumn{9}{|c|}{ Troncos mortos } \\
\hline & \multicolumn{3}{|c|}{$<2,5 \mathrm{~cm}$} & \multicolumn{3}{|c|}{$\geq 2,5 \mathrm{~cm}$} & \multicolumn{3}{|c|}{$\geq 10,0 \mathrm{~cm}$} & \multicolumn{3}{|c|}{$<2,5 \mathrm{~cm}$} & \multicolumn{3}{|c|}{$\geq 2,5 \mathrm{~cm}$} & \multicolumn{3}{|c|}{$\geq 10,0 \mathrm{~cm}$} \\
\hline & $\mathrm{Ag}$ & $\mathrm{Lg}$ & $\mathrm{Rh}$ & $\mathrm{Ag}$ & $\mathrm{Lg}$ & $\mathrm{Rh}$ & $\mathrm{Ag}$ & $\operatorname{Lg}$ & $\mathrm{Rh}$ & $\mathrm{Ag}$ & $\operatorname{Lg}$ & $\mathrm{Rh}$ & $\mathrm{Ag}$ & $\mathrm{Lg}$ & $\mathrm{Rh}$ & $\mathrm{Ag}$ & $\mathrm{Lg}$ & $\mathrm{Rh}$ \\
\hline \multicolumn{19}{|c|}{$\operatorname{DoA}(\%)$} \\
\hline Sítio 1 & 0,06 & 0,38 & 0,55 & 1,16 & 14,3 & 7,66 & 30,4 & 16,5 & 4,46 & $<0,01$ & 0,03 & - & 0,59 & 12,9 & 0,19 & - & 10,9 & - \\
\hline Sítio 2 & 0,20 & 0,01 & 0,03 & 4,84 & 0,27 & 6,10 & 60,6 & 0,70 & 20,7 & 0,25 & $<0,01$ & - & 1,86 & 0,11 & 0,48 & 3,15 & 0,35 & 0,34 \\
\hline \multicolumn{19}{|l|}{ DR (\%) } \\
\hline Sítio 1 & 0,96 & 6,98 & 9,04 & 1,78 & 25,3 & 14,8 & 4,41 & 6,37 & 1,44 & 0,15 & 0,59 & - & 1,74 & 20,7 & 0,89 & - & 4,88 & - \\
\hline Sítio 2 & 7,88 & 0,27 & 1,81 & 18,5 & 0,82 & 13,3 & 17,9 & 0,72 & 15,0 & 9,85 & 0,27 & - & 9,89 & 0,18 & 0,72 & 2,43 & 0,27 & 0,18 \\
\hline
\end{tabular}

$\mathrm{Ag}=$ Avicennia germinans $; \mathrm{Lg}=$ Laguncularia racemosa $; \mathrm{Rh}=$ Rhizophora mangle

no Sítio 2, esses parâmetros foram mais altos para A. germinans (Tab. 8).

A distribuição dos troncos vivos em classes de diâmetro (Tab. 7) mostrou que A. germinans exibiu predomínio na classe $\geq 10,0 \mathrm{~cm}$ no Sítio 1 e na classe intermediária no Sítio 2. L. racemosa apresentou predomínio na classe intermediária em ambos os sítios e R. mangle, na classe intermediária no Sítio 1, e na classe superior no Sítio 2. Quanto à distribuição dos troncos mortos, houve predomínio na classe intermediária para todas as espécies no Sítio $1 \mathrm{e}$ variação entre as classes no Sítio 2 (Tab. 7).

Os resultados obtidos a partir da distribuição dos troncos vivos e mortos, por espécie, em classes de diâmetro de $3 \mathrm{em} 3 \mathrm{~cm}$ mostraram que no Sítio 1 , o número de troncos vivos de $A$. germinans foi maior na classe inicial $(1,0-3,0 \mathrm{~cm})$ e nas classes superiores $(21,1-27,0 \mathrm{~cm})$, ocorrendo troncos mortos apenas nas três primeiras classes diamétricas (Fig. 3A). Neste sítio, L. racemosa exibiu maior representatividade de troncos vivos e mortos nas quatro primeiras classes (Fig. 3B), enquanto que $R$. mangle apresentou maior número de troncos vivos na classe entre 1,0 e $6,0 \mathrm{~cm}$, com praticamente ausência de troncos mortos (Fig. 3C). No Sítio 2, A. germinans mostrou maior representatividade nas duas primeiras classes (Fig. 3D). O número de troncos de L. racemosa foi baixo, neste sítio, sendo registrados apenas nas classes inferiores a $15,0 \mathrm{~cm}$ (Fig. 3E). R. mangle exibiu maior número de troncos vivos nas classes intermediárias $(6,1-15,0 \mathrm{~cm})$, ocorrendo poucos troncos mortos (Fig. 3F).

\section{Discussão}

Sedimento - A condutividade elétrica e o $\mathrm{pH}$ do sedimento foram praticamente constantes entre a franja e o interior da floresta, provavelmente, devido à alta frequiência de inundação em ambas as zonas. $\mathrm{O}$ pH levemente ácido do sedimento superficial deve-se à oxidação de sulfetos, decomposição de serrapilheira, hidrólise de tanino das plantas de mangue (as quais liberam vários tipos de ácidos orgânicos) (Liao 1990) e baixa influência da água marinha. Considerando-se que a condutividade da água do mar é de aproxima-

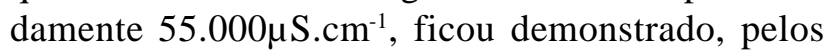
baixos valores de sais solúveis (condutividade) do sedimento (378-1.149 $\left.\mu \mathrm{S} . \mathrm{cm}^{-1}\right)$, que os dois sítios de estudo se encontram sob influência fluvial. É possível que a amostragem realizada ao final período chuvoso (fevereiro), também tenha causado redução de sais no sedimento. Tam et al. (1995), estudando um manguezal na China, observaram que o $\mathrm{pH}$ do sedimento superficial variou entre a acidez e a neutralidade $(4,2$ a 7,0$)$ e o conteúdo de sais solúveis esteve entre 1.400 e $2.200 \mu{\mathrm{S} . \mathrm{cm}^{-1}}^{-}$. Os valores de $\mathrm{pH}$ mais alcalinos em amostras coletadas na margem do canal $(2-10 \mathrm{~m})$, foram atribuídos à variação da frequiência de inundação. Porém, como observado no presente estudo, nenhuma tendência específica foi identificada para os valores de condutividade ao longo do gradiente de inundação.

No Sítio 2, foi observado maior percentual de matéria orgânica, que provavelmente, está relacionado à maior produção de detritos da floresta que é mais madura e/ou à menor lavagem pelas marés neste sítio. O conteúdo de matéria orgânica foi elevado, apesar das características grosseiras do sedimento, mas não houve correlação entre o percentual de matéria orgânica com a fração silte/argila. Alguns estudos têm demonstrado que sedimentos arenosos freqüentemente apresentam baixo percentual de matéria orgânica e menor capacidade de retenção de nutrientes se 
comparados a sedimentos argilosos (Souza et al. 1993; 1996). Possível explicação para os resultados encontrados pode estar relacionada à grande contribuição de matéria orgânica na forma de detritos orgânicos maiores que a fração silte/argila e menores que $2 \mathrm{~mm}$, os quais não se encontram adsorvidos à superfície das partículas finas.
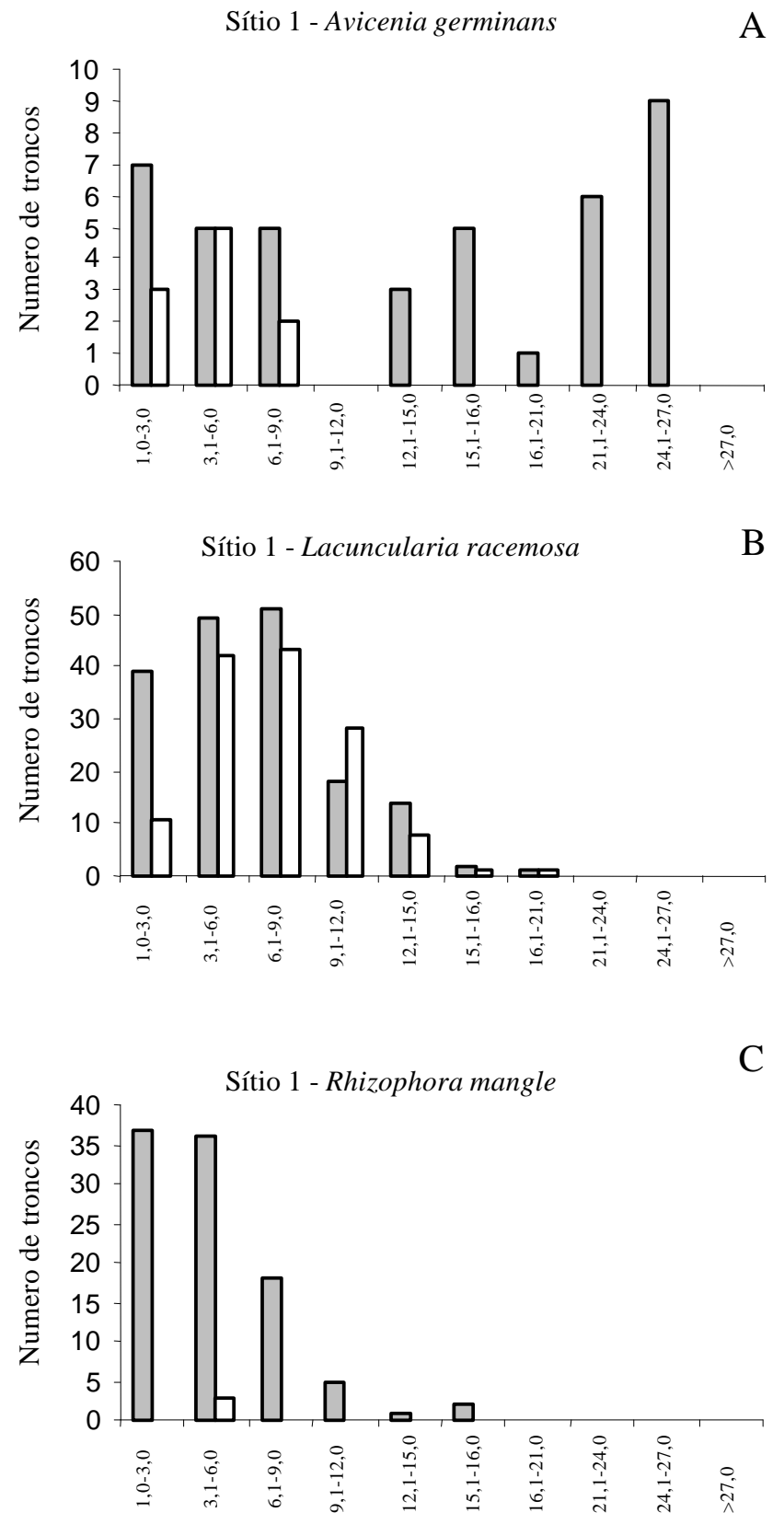

Classe diamétrica $(\mathrm{cm})$

A
Estrutura da vegetação - Os parâmetros estruturais (altura, DAP médio, área basal e densidade) não diferiram, significativamente, entre franja e interior da floresta. A não diferenciação na estrutura da vegetação pode ser devida à alta frequiência de inundação em ambas as zonas, que promove condições ambientais similares, conforme observado nos parâmetros

Sítio 2 - Avicenia germinans

D
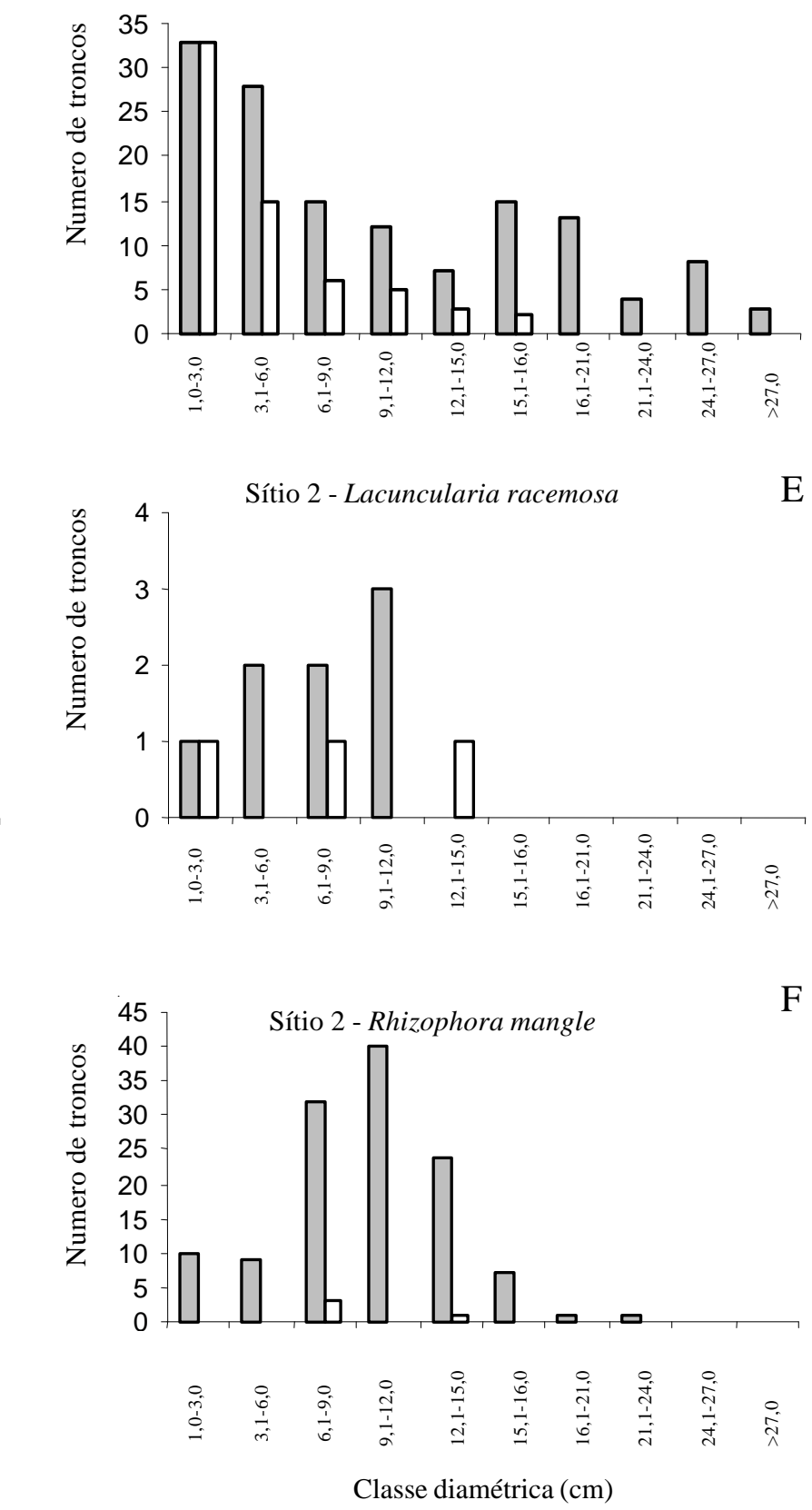

Figura 3. Distribuição dos troncos vivos e mortos, por espécie, em classes de diâmetro de $3 \mathrm{em} 3 \mathrm{~cm}$ nos dois sítios de estudo analisados no manguezal do estuário do rio Paraíba do Sul. Sítio 1: A. Avicennia germinans (vivos $\mathrm{n}=41$ e mortos $\mathrm{n}=10$ ). B. Laguncularia racemosa (vivos $n=174$ e mortos $n=134)$. C. Rhizophora mangle (vivos $n=99$ e mortos $n=3$ ); Sítio 2: D. Avicennia germinans (vivos $n=142$ e mortos $n=64$ ). E. Laguncaria racemosa (vivos $n=8$ e mortos $n=3$ ). F. Rhizophora mangle (vivos $n=124$ e mortos $n=4$ ). $\square=$ Vivos; $\square=$ Mortos. 
Tabela 8. Relação tronco/indivíduo (T/I) e densidade de troncos (troncos.ha ${ }^{-1}$ ) vivos e mortos, por espécie, na franja e no interior da floresta nos dois sítios de estudo analisados no manguezal do estuário do rio Paraíba do Sul, Rio de Janeiro, Brasil (média \pm desvio padrão).

\begin{tabular}{|c|c|c|c|c|c|c|c|}
\hline \multirow[t]{2}{*}{ Sítio/zona } & \multirow[b]{2}{*}{$\mathrm{T} / \mathrm{I}$} & \multicolumn{3}{|c|}{ Densidade de troncos vivos } & \multicolumn{3}{|c|}{ Densidade de troncos mortos } \\
\hline & & $\mathrm{Ag}$ & $\operatorname{Lg}$ & $\mathrm{Rh}$ & $\mathrm{Ag}$ & $\mathrm{Lg}$ & $\mathrm{Rh}$ \\
\hline \multicolumn{8}{|l|}{ Sítio 1} \\
\hline Franja $(n=3)$ & $1,3 \pm 0,1$ & $145 \pm 135$ & $1.845 \pm 505$ & $1.411 \pm 990$ & $100 \pm 0$ & $950 \pm 661$ & $200 \pm 0$ \\
\hline Interior $(n=3)$ & $1,3 \pm 0,2$ & $391 \pm 212$ & $1.048 \pm 523$ & $481 \pm 219$ & $108 \pm 59$ & $1.008 \pm 260$ & - \\
\hline Geral $(n=6)$ & $1,3 \pm 0,2$ & $268 \pm 208$ & $1.446 \pm 564$ & $946 \pm 816$ & $106 \pm 49$ & $979 \pm 451$ & $200 \pm 0$ \\
\hline \multicolumn{8}{|l|}{ Sítio 2} \\
\hline Franja $(n=3)$ & $1,4 \pm 0,1$ & $2.202 \pm 2.074$ & $133 \pm 0$ & $620 \pm 537$ & $1.180 \pm 1.241$ & $33 \pm 0$ & $33 \pm 0$ \\
\hline Interior $(n=3)$ & $1,4 \pm 0,1$ & $767 \pm 613$ & $100 \pm 0$ & $1.350 \pm 705$ & $267 \pm 189$ & $100 \pm 0$ & $67 \pm 47$ \\
\hline Geral $(n=6)$ & $1,4 \pm 0,1$ & $1.628 \pm 1.692$ & $111 \pm 19$ & $1.058 \pm 693$ & $815 \pm 1015$ & $67 \pm 47$ & $55 \pm 39$ \\
\hline
\end{tabular}

$\mathrm{Ag}=$ Avicennia germinans $; \mathrm{Lg}=$ Laguncularia racemosa $; \mathrm{Rh}=$ Rhizophora mangle

Tabela 9. Variação na estrutura da vegetação em diferentes manguezais do Brasil.

\begin{tabular}{lcccl}
\hline Local & DAP médio $(\mathrm{cm})$ & Altura média $(\mathrm{m})$ & Área basal $\left(\mathrm{m}^{2} . \mathrm{ha}^{-1}\right)$ & Fonte \\
\hline São Luís, MA* & 21,2 & 19,8 & 19,4 & Santos $(1986)$ \\
Caravelas, BA* & $5,90-17,8$ & $4,60-9,80$ & $4,00-38,6$ & Schaeffer-Novelli et al. $(1994)$ \\
Conceição da Barra, ES* & $8,12-29,6$ & $5,50-14,8$ & $7,20-30,9$ & Silva et al. $(2000)$ \\
Vitória, ES* & $4,23-18,9$ & $5,30-17,3$ & $5,40-29,8$ & Carmo et al. $(1995)$ \\
Guaratiba, RJ** & $0,79-7,63$ & $2,30-9,33$ & $13,4-61,7$ & Pellegrini et al. $(2000)$ \\
Lagoa da Tijuca, RJ** & $1,49-16,1$ & $3,40-16,7$ & $14,3-41,4$ & Soares $(1999)$ \\
Baía de Guanabara, RJ* & 11,0 & - & 34,9 & Araújo \& Maciel (1979) \\
Baía de Sepetiba, RJ* & 7,8 & 6,10 & 21,6 & Silva et al. $(1991)$ \\
Ilha do Cardoso, SP* & $6,90-12,0$ & $5,70-9,80$ & $16,2-35,6$ & Peria et al. $(1990)$ \\
Este estudo** & $6,29-16,7$ & $6,91-11,8$ & $15,1-51,7$ & 2002 \\
\hline
\end{tabular}

Limite de inclusão: *indivíduos com diâmetro $\geq 2,5 \mathrm{~cm}$; **indivíduos com altura $>1 \mathrm{~m}$

analisados no sedimento. Entretanto, os dois sítios estudados apresentaram características estruturais distintas, uma vez que o Sítio 2 destacou-se pelo melhor desenvolvimento estrutural em termos de altura, DAP médio e área basal. Este resultado reflete o grau de maturidade das florestas, pois os parâmetros determinados no sedimento não explicam as variações encontradas entre os sítios.

No Sítio 2, a floresta é mais madura, havendo maior contribuição em área basal de indivíduos vivos $(88 \%)$ e densidade de troncos vivos (55\%) na classe diamétrica maior que $10,0 \mathrm{~cm}$. No Sítio 1 , a contribuição foi de $68 \%$ para área basal de indivíduos vivos e apenas $17 \%$ para troncos vivos, na mesma classe de diâmetro. Além da maturidade das florestas, as diferenças estruturais também podem ser explicadas pela maior contribuição, em área basal, da espécie L. racemosa no Sítio $1(41 \%)$ em relação ao Sítio $2(1 \%)$, visto que esta espécie dificilmente atinge altos valores de diâmetro. No manguezal do Pontal da Daniela, Florianópolis (SC), a contribuição em área basal viva maior que $10,0 \mathrm{~cm}$ diâm. foi de apenas $24 \%$ (considerando-se os indivíduos $>2 \mathrm{~m}$ alt.). $\mathrm{O}$ baixo percentual foi atribuído à jovialidade da floresta, bem como à aparente incapacidade de $L$. racemosa, que foi a espécie dominante, de atingir valores expressivos de diâmetro (Souza et al. 1993).

Apesar dos parâmetros estruturais das florestas não terem variado entre franja e interior, houve variação na contribuição de cada espécie nas distintas zonas. Levando-se em consideração que as duas zonas apresentam condições ambientais similares, provavelmente, tais diferenças estão associadas à ocorrência de processos sucessionais na comunidade. C. Coelho-Jr. (comunicação pessoal) demonstrou que, embora a composição florística e a estrutura das florestas de mangue possam variar com o gradiente físico-químico local, outros processos, como a sucessão 
ecológica, também devem ser considerados. Para os manguezais de Cananéia (SP), o autor concluiu que a baixa contribuição das espécies $L$. racemosa e A. schaueriana, tanto em área basal, quanto em número de indivíduos, e a dominância de $R$. mangle, indicariam que processos de sucessão estariam ocorrendo na área estudada. De fato, no presente estudo, a distribuição dos troncos em classes de diâmetro de $3 \mathrm{em} 3 \mathrm{~cm}$ indicou que as florestas dos dois sítios estudados no manguezal do estuário do rio Paraíba do Sul encontram-se em estágios sucessionais distintos.

No Sítio 1, onde a floresta é mais jovem, houve maior número de troncos vivos e mortos da espécie L. racemosa. Esta espécie demonstrou elevada contribuição tanto em área basal de indivíduos mortos, quanto em número de troncos mortos, principalmente na zona interna da floresta, onde $A$. germinans foi a espécie dominante. A área basal ou densidade de árvores mortas é parâmetro altamente variável, visto que fatores locais, tais como taxa de crescimento das árvores, intensidade e freqüência de tensores, estabilidade geomorfológica, taxa de decomposição das árvores mortas e diâmetro inicial das árvores, estão relacionados à mortalidade dos indivíduos (Jimenez et al. 1985). Tendo em vista que não foram observadas alterações ambientais no Sítio 1, a competição intra e interespecífica parecem ser a principal causa da mortalidade de árvores de L. racemosa. De acordo com Jimenez et al. (1985), copas fechadas inibem a regeneração de florestas de $L$. racemosa, pois esta espécie é intolerante à sombra. Assim, os resultados levam a crer que a floresta está sofrendo processo de desbaste natural e que L. racemosa está sendo gradualmente substituída por árvores de $A$. germinans e $R$. mangle. No entanto, A. germinans apresentou mortalidade de troncos nas primeiras classes diamétricas, apontando que esta espécie, provavelmente, venha a ser substituída por $R$. mangle, que apresentou grande número de troncos vivos nas duas primeiras classes diamétricas.

No Sítio 2, foi observado cenário distinto, pois a floresta é mais madura, havendo poucos troncos de L. racemosa. A mortalidade de árvores de A. germinans com diâmetros mais reduzidos $(<6 \mathrm{~cm})$ também pode ser devida à competição intra e interespecífica. Embora tenha sido observada baixa representatividade de indivíduos de $R$. mangle nas duas primeiras classes diamétricas (talvez devido a problema de regeneração), é provável que, futuramente, a floresta venha a ser dominada por esta espécie.
Entretanto, torna-se desejável a realização de análise de dinâmica de populações para melhor entendimento do processo de substituição de espécies que parece ocorrer na área estudada.

A relação tronco/indivíduo das florestas analisadas foi próxima a 1. Em geral, florestas bem desenvolvidas, crescendo sob condições mais adequadas, tem relação próxima a esse valor (Schaeffer-Novelli \& Cintrón, 1986). A densidade de troncos no manguezal do estuário do rio Paraíba do Sul foi inferior aos valores encontrados em manguezais sob influência de atividades antrópicas na Lagoa da Tijuca (RJ) (Soares 1999), onde a densidade de troncos vivos variou de 1.250 a 17.000 troncos.ha ${ }^{-1}$, e de troncos mortos de 100 a 18.500 troncos.ha ${ }^{-1}$. A espécie dominante foi $L$. racemosa e houve predomínio de troncos vivos e mortos na classe entre 2,5 e $10,0 \mathrm{~cm}$ diâm. No presente estudo, L. racemosa também demonstrou predomínio na mesma classe diamétrica, mas não foi a espécie dominante.

Jimenez \& Lugo (1985), revisando trabalhos sobre A. germinans, descreveram que a espécie, geralmente, ocorre em áreas menos elevadas, podendo estar presente, também, em locais onde a inundaçãoé menos freqüente. A espécie é encontrada em substratos arenoso, siltoso ou argiloso, sendo o melhor desenvolvimento observado em florestas ribeirinhas, como é o caso do manguezal analisado no presente estudo. A dominância de A. germinans demonstra que o manguezal do estuário do rio Paraíba do Sul difere de outros manguezais do Estado do Rio de Janeiro, onde a co-dominância de $R$. mangle e L racemosa é destacada por Silva et al. (1991), Soares (1999) e Pellegrini et al. (2000). No manguezal do estuário do rio Paraíba do Sul, durante o período de baixa vazão, o ecossistema estaria submetido a regime de inundação semelhante aos dos manguezais de planícies de marés, propriamente ditas. Nos meses de cheia do rio, o sedimento do manguezal tenderia a permanecer grande parte do tempo submerso, transformando-se temporariamente em planície de inundação, com predomínio de água doce. Aporte maior de água salgada nessas condições ficaria restrito a períodos de marés de sizígia. Assim, a alternância entre planície de maré e de inundação confere características distintas ao manguezal estudado, em relação a outros manguezais regidos principalmente pelo regime de marés.

No manguezal do estuário do rio Paraíba do Sul, várias espécies não típicas como Acrostichum aureum, Dalbergia ecastophyla, Hibiscus pernambucensis e Montrichardia arborecens colonizam o sedimento do manguezal, mesclando-se com espécies típicas de 
mangue, indicando a presença de água doce. Os baixos valores de condutividade elétrica do sedimento também confirmam a menor influência marinha. A baixa salinidade associada ao fato do sedimento ser mais consistente neste manguezal favorece a remoção da vegetação para fins pecuários, uma das atividades que tem causado grande degradação a este ecossistema na região. Em sedimentos predominantemente lodosos, com alta salinidade, as colonizações por gramíneas e gado costumam fracassar porque as plantas de mangue retornam com vigor, ou porque o gado não encontra substrato firme no terreno alagadiço. No manguezal do rio Paraíba do Sul, contudo, o sedimento mais consistente permite que criadores encontrem condições favoráveis a sua atividade, inibindo a auto-regeneração do ecossistema (A. Sofiatti, comunicação pessoal).

Pool et al. (1977) demonstraram a relação direta entre desenvolvimento estrutural e índice de precipitação para manguezais no Caribe. Neste estudo foi observado que em regiões de clima úmido, o desenvolvimento da floresta é significativamente mais elevado do que em regiões de clima seco. $\mathrm{Na}$ área de clima úmido na Costa Rica (precipitação anual de $3.000 \mathrm{~mm}$ ), considerando-se os troncos com diâmetros $\geq 2,5 \mathrm{~cm}$, a área basal atingiu $96,4 \mathrm{~m}^{2} \cdot \mathrm{ha}^{-1}$, com dominância de Pterocarpus officinalis na floresta do tipo ribeirinho, enquanto que na área de clima seco (precipitação anual de $1.800 \mathrm{~mm}$ ) a área basal foi de 23-32 $\mathrm{m}^{2}$.ha ${ }^{-1}$, com dominância de $R$. mangle na floresta do tipo franja e Pelliciera rhizophorae, na floresta ribeirinha. Os resultados do presente estudo (precipitação anual entre 1.000 e $1.250 \mathrm{~mm}$ ) demonstram que o desenvolvimento estrutural do manguezal é equiparado aos das regiões de clima mais seco do Caribe.

Na Tabela 9 é demonstrada a variação na estrutura da vegetação em diferentes manguezais do Brasil. As características estruturais observadas aqui não se equiparam àquelas encontradas no Estado do Maranhão, onde a amplitude das marés é maior e as temperaturas são mais altas. Observa-se, contudo, que os valores do presente estudo enquadram-se como similares a alguns parâmetros em manguezais dos Estados da Bahia, Espírito Santo, Rio de Janeiro e São Paulo (Peria et al. 1990; Schaeffer-Novelli et al. 1994; Carmo et al. 1995; Soares 1999; Silva et al. 2000), onde há regime de micro a meso-marés. Os resultados obtidos foram superiores aos dos manguezais das Baías de Guanabara e Sepetiba, RJ (Araújo \& Maciel 1979; Silva et al. 1991). Entretanto, é importante ressaltar que a comparação entre manguezais diferentes é tarefa difícil, dada a falta de padrão metodológico e critérios técnicos claramente definidos nos estudos. Além disso, as regiões apresentam características ambientais distintas e os manguezais estão sujeitos a diferentes tipos de tensores que influenciam no desenvolvimento estrutural das florestas de mangue (Lugo \& Snedaker 1974).

Os resultados descritos neste estudo contribuem com informações sobre a estrutura da comunidade vegetal do manguezal estudado. Os dados obtidos demonstraram que a área de manguezal analisada no estuário do rio Paraíba do Sul encontra-se em bom estado de conservação e apresenta melhor desenvolvimento estrutural quando comparado a outros manguezais do litoral fluminense, tais como os encontrados nas Baías de Guanabara e Sepetiba. No entanto, devido à grande influência fluvial, o manguezal do estuário do rio Paraíba do Sul é bastante distinto dos outros manguezais do Estado do Rio de Janeiro, por isso, torna-se desejável a realização de estudos mais detalhados, com maior número amostral, para melhor caracterização da estrutura da floresta e para verificar o padrão de distribuição espacial das espécies vegetais.

\section{Agradecimentos}

À FAPERJ (Fundação de Amparo à Pesquisa do Estado do Rio de Janeiro), pela bolsa de mestrado concedida à primeira Autora (Proc. E-26/152.031/ 2001); ao CNPq (Proc. n. 420.110/97-6), pelo auxílio financeiro concedido ao segundo Autor; ao Laboratório de Ciências Ambientais (LCA), da Universidade Estadual do Norte Fluminese (UFNF), pela infraestrutura fornecida para o desenvolvimento do trabalho; a Fernando Luiz de Carvalho e Silva, pela elaboração do produto de geoprocessamento; a Diogo Oliveira dos Santos, Oscar Nascimento Cardoso, técnicos e motoristas da UENF, pelo apoio nos trabalhos de campo e de laboratório.

\section{Referências bibliográficas}

Araújo, D.S.D. \& Maciel, N.C. 1979. Os manguezais do recôncavo da Baía de Guanabara. Cadernos FEEMA, Série Técnica 10: 1-113.

Carmo, T.M.S.; Brito-Abaurre, M.G.; Senna-Melo, R.M.; Zanotti-Xavier, S.; Costa, M.B. \& Horta, M.M.M. 1995. Os manguezais da Baía Norte de Vitória, Espírito Santo: um ecossistema ameaçado. Revista Brasileira de Biologia 55(4): 801-808.

Cintrón, G.; Lugo, A.E. \& Martinez, R. 1980. Structural and functional properties of mangrove forests. Pp. 53-67. In: Symposium Signaling the Complexion of the Flora of Panama. University of Panama, Panama. 
DHN. Diretoria de Hidrografia e Navegação. Tábuas das marés. http://www.dhn.mar.mil.br/ dhn/servicos.htm em 01/06/01.

DNAEE. Departamento Nacional de Águas e Energia Elétrica. 1993. Projeto Paraíba do Sul: Relatório Principal da Fase B. Ministério de Minas e Energia, Rio de Janeiro.

EMBRAPA, Centro Nacional de Pesquisa de Solos. 1997. Manual de Métodos de Análise de Solo. EMBRAPACNPS, Brasil, Rio de Janeiro.

FEEMA. Fundação Estadual de Engenharia do Meio Ambiente. 1980. Relatório técnico sobre manguezal. RT 1123.

Fry, B.; Bern, A.L.; Ross, M.S. \& Meeder, J.F. 2000. d ${ }^{15} \mathrm{~N}$ studies of nitrogen use by the red mangrove, Rhizophora mangle L. in South Florida. Estuarine, Coastal and Shelf Science 50: 291-296.

Jimenez, J. A. \& Lugo, A. E. 1985. Avicennia germinans (L.) L. Black mangrove. Avicenniaceae. Verbena family. UNESCO, SO-ITF-SM 4: 6 .

Jimenez, J.A.; Lugo, A.E. \& Cintrón, G. 1985. Tree mortality in mangrove forests. Biotropica 17(3): 177-185.

Kjerfve, B. \& Lacerda, L.D. 1993. Mangroves of Brazil. Pp. 245-272. In: L.D. Lacerda (ed.). Conservation and sustainable utilization of mangrove forests in Latin America and Africa Regions. International Society for Mangrove Ecosystems. Technical reports, v.2, ITTO TS-13, v.1.

Liao, J.F. 1990. The chemical properties of the mangrove Solonchak in the northeast part of Hainan Island. The Acta Scientiarum Naturalium Universititis Sunyatseni (Suppl.) 9(4): 67-72.

Lugo, A.E. \& Snedaker, S.C. 1974. The ecology of mangroves. Annual Review of Ecology and Systematic 5: 39-64.

Menezes, L.F.T.; Peixoto, A.L. \& Maciel, N.C. 2000. A riqueza ameaçada dos manguezais. Ciência Hoje 27(158): 63-67.

Oliveira, V.F.; Soares, M.L.G.; Pellegrini, J.A.C.; Silva-Jr., C.M.G.; Chaves, F.O. \& Corrêa, F.M. 2000. Dinâmica de comunidade de Avicennia schaueriana e Laguncularia racemosa na interface manguezal/planície hipersalina (Guaratiba-RJ). Pp. 255-261. In: Anais do V Simpósio de Ecossistemas Brasileiros. ACIESP Ed. v.2, São Paulo.

Pellegrini, J.A.C.; Soares, M.L.G.; Corrêa, F.M. \& SchaefferNovelli, Y. 2000. Caracterização da planície hipersalina (apicum) associada a um bosque de mangue em Guaratiba, Baía de Sepetiba, RJ. Pp. 262-269. In: Anais do V Simpósio de Ecossistemas Brasileiros. ACIESP Ed. v.2, São Paulo.

Peria, L.C.S.; Fernandez, P.P.C.P.; Menezes, G.V.; Grasso, M. \& Tognella, M.M.P. 1990. Estudos estruturais comparativos entre bosques de mangue impactados (Canal da Bertioga) e não impactados (Ilha do Cardoso), Estado de São Paulo. Pp. 183-193. In: Anais do Simpósio de Ecossistemas da Costa Sul e Sudeste Brasileira, ACIESP Ed. v.2, São Paulo.
Pool, D.J.; Snedaker, S.C. \& Lugo, A.E. 1977. Structure of mangrove forests in Florida, Puerto Rico, México and Costa Rica. Biotropica 9(3): 195-212.

Santos, M.C.F.V. 1986. Considerações sobre a ocorrência de Rhizophora harrisonii Leechamn e Rhizophora racemosa G.F.W. Meyer, no litoral do Estado do Maranhão, Brasil. Boletim do Laboratório de Hidrobiologia 7: 71-91.

Schaeffer-Novelli, Y. \& Cintrón, G. 1986. Guia para estudo de áreas de manguezal: estrutura, função e flora. Caribbean Ecological Research, São Paulo.

Schaeffer-Novelli, Y.; Peria, L.C.S.; Menezes, G.V.; Grasso, M.; Soares, M.L.G. \& Tognella, M.M.P. 1994. Manguezais brasileiros, Caravelas, Estado da Bahia. Pp. 324-332. In: Anais do III Simpósio de Ecossistemas da Costa Brasileira. Subsídios a um gerenciamento ambiental. ACIESP Ed. v.1, São Paulo.

Schaeffer-Novelli, Y.; Cintrón-Molero, G.; Adaime, R.R. \& Camargo, T.M. 1990. Variability of mangrove ecosystems along the Brazilian coast. Estuaries 13(2): 204-218.

Silva, C.A.R.; Lacerda, L.D.; Silva, L.F.F. \& Rezende, C.E. 1991. Forest structure and biomass distribution in a red mangrove stand in Sepetiba Bay, Rio de Janeiro. Revista Brasileira Botânica 14: 21-25.

Silva, M.A.B.; Bernini, E. \& Carmo, T.M.S. 2000. Estrutura da floresta ribeirinha do manguezal do rio São Mateus, Conceição da Barra, Espírito Santo. Pp. 234-246. In: Anais do V Simpósio de Ecossistemas Brasileiros. ACIESP Ed. v.2, São Paulo.

Smith, T.J. III. 1992. Forest structure. Pp. 101-136. In: A.I. Robertson \& D.M. Alongi (eds.). Tropical mangrove ecosystems. Coastal and estuarine series. American Geophysical Union, Washington, USA.

Soares, M.L.G. 1999. Estrutura vegetal e grau de perturbação dos manguezais da Lagoa da Tijuca, Rio de Janeiro, RJ, Brasil. Revista Brasileira de Biologia 59(3): 503-515.

Souza, H.F.; Guedes, M.L.S.; Oliveira, S.S. \& Santos, E.S. 1996. Alguns aspectos fitossociológicos e nutricionais do manguezal da Ilha de Pati, Bahia, Brasil. Sitientibus 15: 151-165.

Souza, M.L.R.; Falkenberg, D.B.; Amaral, L.G.; Fronza, M.; Araújo, A.C. \& Sá, M.R. 1993. Vegetação do Pontal da Daniela, Florianópolis, SC, Brasil. II Fitossociologia do manguezal. Insula 22: 107-142.

Tam, N.F.Y.; Li, S.H.; Lan, C.Y.; Chen, G.Z.; Li, M.S. \& Wong, Y.S. 1995. Nutrients and heavy metals contamination of plants and sediments in Futian mangrove forest. Hydrobiologia 295: 149-158. 